\title{
Can Alfacalcidol ameliorate Atorvastatin-induced myopathy in adult male rats? A histological study
}

\author{
Original \\ Article \\ Dalia Fathy El-Deeb, Mira Farouk Youssef, Marwa Mohamed Yousry, Amy \\ Mohamed Ahmed
}

Department of Histology, Faculty of Medicine, Cairo University, Cairo, Egypt

\begin{abstract}
Introduction: Atorvastatin (Ator), is the treatment of choice for reducing blood cholesterol. Most adverse effects associated with Statins therapy are muscle-related. Alfacalcidol (ALF), a vitamin D analog commonly used in osteoporosis; showed beneficial effects beyond the skeleton including muscle.

Aim of the work: Investigating the possible protective effect of ALF in Atorvastatin induced myopathy in rats.

Materials and Methods: Twenty-one adult male albino rats were divided equally into 3 groups: Group I (control). Group II (Ator): received Atorvastatin $(10 \mathrm{mg} / \mathrm{kg} /$ day). Group III (Ator-ALF): received Ator concomitantly with Alfacalcidol $(0.5 \mu \mathrm{g} / \mathrm{kg} /$ day $)$. After 4 weeks of daily oral medications administration, blood samples from all rats were analyzed for creatine phosphokinase (CPK). The middle parts of biceps femoris muscles were processed for paraffin blocks for Hematoxylin and Eosin stain and cytochrome $\mathrm{C}$ immunohistochemical stain that subjected to morphometric and statistical studies. Moreover, resin blocks were processed for semithin and ultrathin sections examination.

Results: In group II, light microscopic examination revealed fragmented and tapered muscle fibers, in addition to loss of regular pattern of transverse striation. Many fibers in transverse section acquired an irregular outline. Statistically, elevated CPK level, decreased mean muscle fiber diameter and increased mean area \% of cytochrome C immunoreactivity compared to the control were recorded. Electron microscopic examination showed dissolution of many myofibrils and mitochondria either disfigured giant or with destructed cristae. However, group III showed muscle fibers that are almost comparable to the control group with clear transverse striations. That is confirmed statistically by decreased CPK level, increased mean muscle fiber diameter and decreased mean area \% of cytochrome C immunoreactivity versus group II. While ultrastructurally, few areas of myofibrillar dissolution were noted.

Conclusion: Alfacalcidiol has a protective effect on Ator induced myopathy confirmed by the biochemical analysis, light and electron microscopic examination as well as via morphometric studies.
\end{abstract}

Received: 29 April 2018, Accepted: 03 May 2018

Key Words: Alfacalcidol, atorvastatin, cytochrome C, myopathy.

Corresponding Author: Marwa Mohamed Yousry, Department of Histology, Faculty of Medicine, Cairo University, Cairo, Egypt, Tel.: +201006763862, E-mail: marwa_yousry209@yahoo.com.

ISSN: $1110-0559$, Vol. 41, No. 3

\section{INTRODUCTION}

Cardiovascular diseases (CVD) seem to be the major cause of disability and deaths in the whole world. The leading cause of such disease is the development of lipid plagues in the form of thrombus ${ }^{[1]}$. Statins' therapy, which is generally safe and well tolerated, is considered the cornerstone for prevention and treatment of $\mathrm{CVD}^{[2]}$. Statins significantly reduced the risk of acute myocardial infarction, stroke and cardiovascular morbidity and mortality ${ }^{[3]}$.

The 3-hydroxy-3-methyl glutaryl-coenzyme A (HMG$\mathrm{CoA}$ ) reductase is an enzyme controlling the cholesterol synthesis pathway ${ }^{[4]}$. Statins have the ability to inhibit the enzyme HMG-CoA reductase, and thus lower synthesis of low-density lipoprotein cholesterol (LDL-C) $)^{[5]}$. They also possess beneficial effects on other lipid parameters that include a possible rise of high-density lipoprotein cholesterol (HDL-C) concentration and lowering of triglyceride concentration ${ }^{[6]}$. In addition, they could attenuate vascular inflammation, improve function of endothelial cell, lower vascular smooth muscle cell (VSMC) proliferation and suppress platelet aggregation ${ }^{[7]}$.

There are two types of Statins: lipophilic (Atorvastatin, Simvastatin, Lovastatin, Fluvastatin, and Cerivastatin) and hydrophilic (Pravastatin and Rosuvastatin). The uptake of hydrophilic Statins by hepatocyte is quite extensive due to carrier-mediated uptake which is considered so efficient and specific to liver cells. Therefore, hydrophilic Statins show greater hepatic selectivity and less widespread tissue distribution. On the other hand, lipophilic Statins are distributed not only in hepatocytes through facilitated 
passive diffusion but also exhibited widespread tissue distribution that may be beneficial as they were able to decrease proliferation of VSMC in a dose-dependent manner. However, hydrophilic Pravastatin showed no effect on VSMC ${ }^{[7]}$. From the aforementioned facts, it was obvious that lipophilic Statins exhibit higher distribution in non-hepatic cells, and are more likely to affect muscles ${ }^{[8]}$.

Statins therapy affects liver, kidneys and muscular systems, whereas the skeletal muscle was the most commonly affected ${ }^{[9,}{ }^{10]}$. Many patients cannot obtain the lower level of cholesterol at low doses of Statins, subsequently they use higher doses, thus the risk of myopathy is elevated ${ }^{[1]}$.

Alfacalcidol (ALF), $1 \alpha$ hydroxyl vitamin D 3, is a synthetic vitamin D analog regulating the calcium, and is frequently utilized to treat osteoporosis ${ }^{[12]}$. Additionally, it has a unique pattern of pleiotropic effects on, e.g. muscle, parathyroid, gut, and brain ${ }^{[13]}$. ALF is considered one of steroidal vitamin D receptor (VDR) agonists. Since it possesses $\mathrm{OH}$ group in $1 \alpha$ position, it shows the highest specificity of binding to VDR in muscle ${ }^{[14]}$. Vitamin D supplementation for hypercholesterolemic patients, who are intolerant to Statins due to myositis-myalgia, allows re-administration of Statins without having recurrent myositis-myalgia. This indicated a reversible interaction between vitamin $\mathrm{D}$ and Statins on skeletal muscles ${ }^{[15]}$. Yet, ALF role on Statins-induced myopathy has not been examined. Therefore, the present work was planned to investigate the possible protective effect of Alfacalcidol (active metabolite of vitamin D) on Atorvastatin-induced myopathy in adult male albino rats.

\section{MATERIALS AND METHODS}

\section{(I) Drugs:}

Atorvastatin: Trade name ATOR, manufactured by Egyptian Int. Pharmaceutical Industries Co., in the form of tablets (each $20 \mathrm{mg}$ ). The drug prepared by crushing and dissolving it in distilled water ${ }^{[16]}$.

Alfacalcidol (ALF): Trade name BON-ONE, manufactured by Minipharm Egypt, in the form of tablets (each $1 \mu \mathrm{g}$ active ingredient) that were crushed and dissolved in distilled water ${ }^{[17]}$.

\section{(II) Animals:}

Twenty-one adult male albino rats, 3 months old with an average weight of 200 grams were used in this study. They were housed in the Animal house of Kasr Al-Aini Faculty of Medicine, Cairo University and treated in accordance with guidelines approved by the Animal use committee of Cairo University. Rats were provided with ordinary rat chow, bred at controlled temperature $(24 \pm$ $1{ }^{\circ} \mathrm{C}$ ), with normal light-dark cycle. All animals were kept under the same environmental conditions and had free access to water and food.

\section{(III) Experimental design:}

The rats were divided equally into 3 groups, 7 each: Group I (Control group): received daily $0.5 \mathrm{ml}$ distilled water. Group II (Ator-treated group): given Atorvastatin at a dose of $(10 \mathrm{mg} / \mathrm{kg} /$ day $)$ for 4 weeks ${ }^{[18]}$. Each rat received $0.5 \mathrm{ml}$ distilled water containing $2 \mathrm{mg}$ Ator. Group III (Ator and ALF treated group): Rats of this group received Ator as in group II concomitantly with Alfacalcidol $(0.5 \mu \mathrm{g} /$ $\mathrm{kg} /$ day $)^{[12]}$ for 4 weeks ${ }^{[19]}$. Each rat received daily $0.5 \mathrm{ml}$ distilled water containing $0.1 \mu \mathrm{g}$ ALF.

All drugs were freshly prepared and were given daily by oral gastric gavage starting from the first day of the experiment until sacrifice.

\section{(IV) Experimental procedure:}

\section{Biochemical investigations:}

At the end of experiment just before sacrifice, blood samples were drawn from tail veins of all rats and collected in heparinized capillary tubes. Samples were analyzed for creatine phosphokinase (CPK), a marker of muscle damage, at the Department of Biochemistry, Faculty of Medicine, Cairo University using RayBio ${ }^{\circledR}$ creatine kinase (CK) Activity Colorimetric Assay Kit (catalogue \#: 68CLCK-S100), United States.

\section{Histological studies:}

Animals from all groups were anesthetized by intraperitoneal (IP) injection of phenobarbital $(80 \mathrm{mg} / \mathrm{kg})^{[20]}$. Specimens from the middle part of biceps femoris muscle of both limbs were dissected and excised. Specimens were divided into 2 parts:

\section{A-Part one for light microscopic (LM) study:}

Specimens from both limbs were fixed in $10 \%$ buffered formalin solution for 24 hours, dehydrated in ascending grades of ethanol and embedded in paraffin. Sections of $6 \mu \mathrm{m}$ were subjected to: Hematoxylin \& eosin (H\&E) stain ${ }^{[21]}$ and immunohistochemical staining for cytochrome $\mathrm{C}$ antibody, which plays an important role in initiation of apoptosis upon its release from mitochondria to the cytoplasm ${ }^{[22]}$. Immunohistochemical staining was performed using the streptavidin-biotin peroxidase complex technique ${ }^{[23]}$.

For immunohistochemical stain, antigen retrieval was 
performed by boiling the sections for $10 \mathrm{~min}$ in $10 \mathrm{mM}$ citrate buffer (AP9003) at $\mathrm{pH}$ 6.0. This was followed by blockage of the endogenous peroxidase activity by incubating the sections in hydrogen peroxide for $15 \mathrm{~min}$. Then probed with a cytochrome $\mathrm{C}$ mouse monoclonal antibody (catalog number MA5-11674) diluted in 3\% bovine serum albumin - phosphate buffered saline (BSA-PBS) at a dilution of $1: 100$ for 1 hour at $37^{\circ} \mathrm{C}$ in a humidified chamber. Ultravision detection system (TP-015-HD) was used to complete immunostaining. Tissues were counterstained with Mayer's hematoxylin (TA-060-MH). Primary antibody, citrate buffer, Ultravision detection system and Mayer's hematoxylin were purchased from Labvision Thermo Scientific, Fremont, California, USA. Based on data by the antibody manufacturer, the positive tissue control was specimens of human heart and mouse skeletal muscle tissue. Positive cytochrome $\mathrm{C}$ reaction appeared cytoplasmic. Negative controls were obtained by skipping the application of the primary antibody.

\section{B-Part two for electron microscopic (EM) study:}

Small specimens from biceps femoris from right limb were cut into small fragments $\left(0.5-1.0 \mathrm{~mm}^{3}\right)$, prefixed in $2.5 \%$ glutaraldehyde for 2 hours. Thereafter, were postfixed in $1 \%$ osmium tetroxide in $0.1 \mathrm{M}$ phosphate buffer at $\mathrm{pH} 7.4$ and $4{ }^{\circ} \mathrm{C}$ for 2 hours. Dehydration and resin embedding were done to obtain resin blocks ${ }^{[23]}$. Semithin $(1 \mu \mathrm{m})$ and ultrathin $(60-90 \mathrm{~nm})$ sections were cut using a Leica ultracut (UCT) (Glienicker, Berlin, Germany) at the Electron Microscope Research Unit, Histology Department, Faculty of Medicine, Cairo University. The semithin sections were stained with toluidine blue (1\%) and examined by LM, while ultrathin ones were stained with uranyl acetate then lead citrate ${ }^{[24]}$ and examined by transmission electron microscope [TEM] (JEOL JEM1400, Japan) at the Electron Microscope Research Unit, Faculty of Agriculture, Cairo University.

\section{C-Morphometric studies:}

Ten non-overlapping fields from different sections of each group were used to measure the following parameters:

- Diameter of longitudinal section (L.S.) of skeletal muscle fibers in H\&E stained sections $x 100$.

- Area percent of cytochrome $\mathrm{C}$ positive reaction in cytochrome $\mathrm{C}$ immunostained sections $\mathrm{x} 100$.

This was done using Leica Qwin-500 LTD-software image analysis computer system (Cambridge, England) at the Department of Histology, Faculty of Medicine, Cairo University.

\section{D-Statistical analysis:}

This was done for the biochemical and morphometric measurements using "IBM SPSS statistics 21" and the data were reported as mean \pm standard deviation (SD). One-way analysis of variance (ANOVA) followed by "Tuckey" posthoc test were used to determine the statistical significance $(P<0.05 \text { was considered significant })^{[25]}$.

\section{RESULTS}

\section{I) General observation:}

No deaths were observed in the rats during the experiment.

\section{(II) Biochemical results and statistical analysis:}

The mean value of serum CPK was significantly increased in group II when compared to group I. While group III showed lower levels than group II and the difference was statistically significant, additionally non-significant difference was recorded versus group I (Table 1).

\section{(III) Histological results:}

\section{Group I (Control Group):}

Hematoxylin and Eosin stained transverse sections (T.S.) obtained from biceps femoris muscle demonstrated muscle fibers arranged into bundles and separated by connective tissue (C.T) perimysium. The individual muscle fibers were polygonal with peripheral nuclei and were surrounded by C.T. endomysium (Fig. 1A). In longitudinal sections (L.S.), muscle fibers appeared parallel regularly arranged and possessed peripheral pale oval nuclei (Fig. 1B).

Regarding semithin sections stained with toluidine blue, L.S. of skeletal muscle showed cylindrical regularly arranged muscle fibers with regular transverse striations across the whole thickness of the muscle fiber and peripheral oval vesicular nuclei with prominent nucleoli. Blood capillary could also be noted (Fig. 1C).

Immunohistochemically stained sections showed minimal sarcoplasmic immunoreactivity for cytochrome C (Fig. 1D).

Ultrathin sections of rats' biceps femoris muscle showed parallel regular arrangement of skeletal muscle fibers with longitudinal parallel myofibrils and peripherally located elongated euchromatic nuclei. The myofibril appeared with characteristic striations of alternating light and dark bands. The more electron-dense A band possessed a narrow, less electron-dense $\mathrm{H}$ zone bisected by $\mathrm{M}$ line, and the lucent $\mathrm{I}$ band had a darker $\mathrm{Z}$ line. Additionally the mitochondria appeared intermyofibrillar around the $\mathrm{Z}$ line and the sarcoplasmic reticulum cisternae were present at the A-I junction (Figs 2A, 2B).

\section{Group II (Ator-treated):}

Histological examination of different fields of $\mathrm{H} \& \mathrm{E}$ stained T.S. revealed many fibers that acquired an irregular 
outline rather than polygonal. Others were rounded and were surrounded by a halo of clear external rims. Focal areas of the sarcoplasm of different muscle fibers appeared either deeply acidophilic or lightly stained in others. The C.T. endomysium appeared wide (Fig. 3A). In L.S., disorganized, fragmented and discontinued muscle fibers were observed. Other muscle fibers were tapered to the extent of separation. Darkly stained nuclei as well as pale centrally located ones were shown (Fig.3B).

In semithin L.S., the muscle fibers demonstrated loss of transverse striations with focal areas of sarcoplasmic dissolution as well as areas of deep sarcoplasmic staining. Additionally, there were attenuated muscle fibers having disorganized myofibrils and dark nuclei (Figs. 3C, D).

Examination of cytochrome $\mathrm{C}$ immunohistochemically stained sections revealed positive immunoreaction that was widely extended in the sarcoplasm in most of muscle fibers (Fig. 3E).

Examination of TEM sections revealed marked degeneration in most areas of biceps femoris muscle in the form of lysis and dissolution of many myofibrils or loss of the regular pattern of alternating dark A band and light I band with disrupted, disorganized or lost $\mathrm{Z}$ line, and loss of parts of M line. Some subsarcolemally located nuclei with chromatin clumps were noted. The mitochondria appeared disfigured and giant among myofibrils or with destructed cristae. Moreover, the cisternae of sarcoplasmic reticulum were dilated (Figs. 4A-4D).

\section{Group III (Ator and ALF treated group):}

Examination of H\&E stained T.S. showed bundles of apparently normal polygonal muscle fibers, while few muscle fibers appeared rounded with deeply eosinophilic sarcoplasm (Fig. 5A). L.S. showed regularly arranged parallel muscle fibers. Some nuclei were peripheral and oval; and others were pale and centrally located. In addition, few dark nuclei could be seen (Fig. 5B).

As regards the semithin sections, the T.S. demonstrated polygonal muscle fibers and mast cells near blood capillaries (Fig.5C). In L.S. the muscle fibers appeared almost comparable to the control group with clear transverse striations. However, few limited areas of sarcoplasmic dissolution were still noted (Fig.5D).

Cytochrome C immunohistochemically stained sections showed scattered areas of positive sarcoplasmic immunoreactivity in some examined muscle fibers (Fig. 5E).

Ultrastructurally, skeletal muscle sections revealed parallel myofibrils arranged in register across the width of a muscle fiber. In addition, there were clear regular striation nearly similar to that of the control group consisted of the dark A band bisected by M line, and the light I band with a darker $\mathrm{Z}$ line. However, few areas of myofibrillar dissolution, lost $\mathrm{Z}$ line and peripherally located nuclei with clumped chromatin were seen. Examination of sections of this group also showed intermyofibrillar mitochondria either normal or with fragmented cristae and apparently normal sarcoplasmic reticulum cisternae (Figs.6A and 6B).

\section{(IV) Morphometric results:}

The mean diameter of L.S. skeletal muscle fibers of group II revealed significant decrease versus group I. However, group III represented a significant increase than group II and a non-significant decrease versus control group. Regarding the mean area percent of cytochrome $\mathrm{C}$ immunoreaction, a significant increase in group II versus group I was recorded. On the other hand, group III showed a significant decrease when compared to group II and a non-significant increase than control group (Table 2).

Table 1: Mean values $( \pm \mathrm{SD})$ of serum CPK expressed as (IU/L) in all studied groups.

\begin{tabular}{lccc}
\hline Parameters & Control & Ator group & Ator-ALF group \\
\hline CPK & $123.9 \pm 4.6$ & $284.0 \pm 11.9^{*}$ & $136.4 \pm 16.4^{\square}$ \\
\hline
\end{tabular}

* significant compared to control group. ${ }^{\square}$ significant compared to Ator group.

Table 2: Mean values $( \pm \mathrm{SD})$ of morphometric parameters in all studied groups.

\begin{tabular}{lcc}
\hline Parameters & Control & Ator group \\
\hline Mean diameter of L.S. skeletal muscle fibers $(\mu \mathrm{m})$ & $54.8 \pm 6.12$ & $25.1 \pm 5.9^{*}$ \\
Mean area percent of cytochrome C immunoreaction & $0.45 \pm 0.14$ & $47.04 \pm 9.3^{\square}$ \\
\hline
\end{tabular}

*significant compared to control group, ${ }^{\square}$ significant compared to Ator group. 

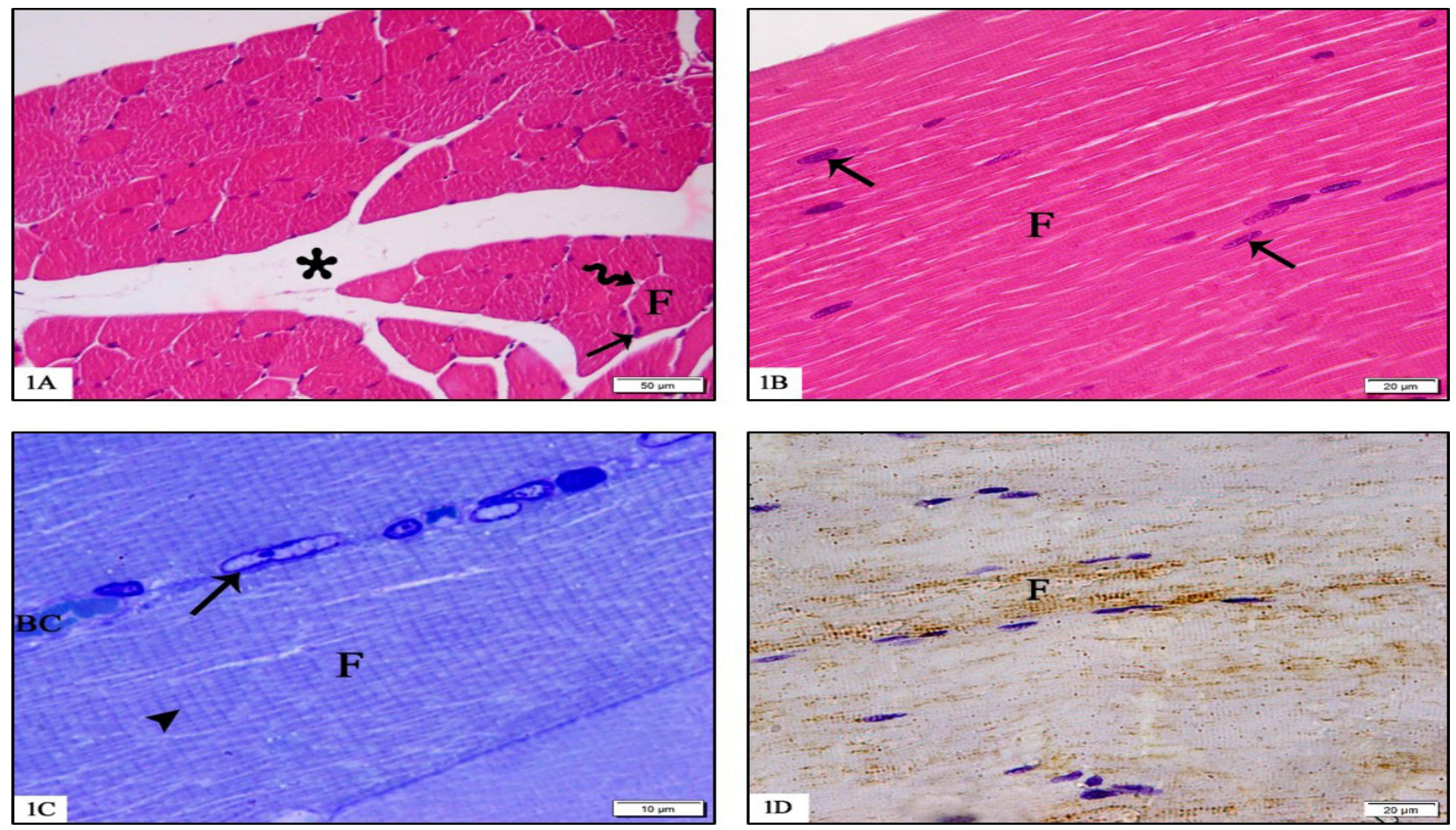

Fig. 1: Light photomicrographs of the control group sections showing: A: Transverse section (T.S.) of bundles of polygonal skeletal muscle fibers (F) that are separated by CT perimysium (star). The individual muscle fibers exhibit peripheral nuclei (arrow) and are separated by CT endomysium (wavy arrow) (H\&E x200). B: longitudinal section (L.S.) illustrating regularly parallel arranged muscle fibers (F) with peripheral pale oval nuclei (arrows) (H\&E x400). C: Semithin L.S. showing cylindrical regularly arranged muscle fibers (F) with regular transverse striations (arrowhead) across the whole thickness of the muscle fiber and peripheral oval vesicular nuclei with prominent nucleoli (arrow). A blood capillary (BC) can also be seen (Toluidine blue x1000). D: Minimal cytochrome C immunoreaction in the sarcoplasm of muscle fibers $(\mathrm{F})$ is demonstrated (Immunohistochemical stain for cytochrome $\mathrm{C} \times 400$ ).
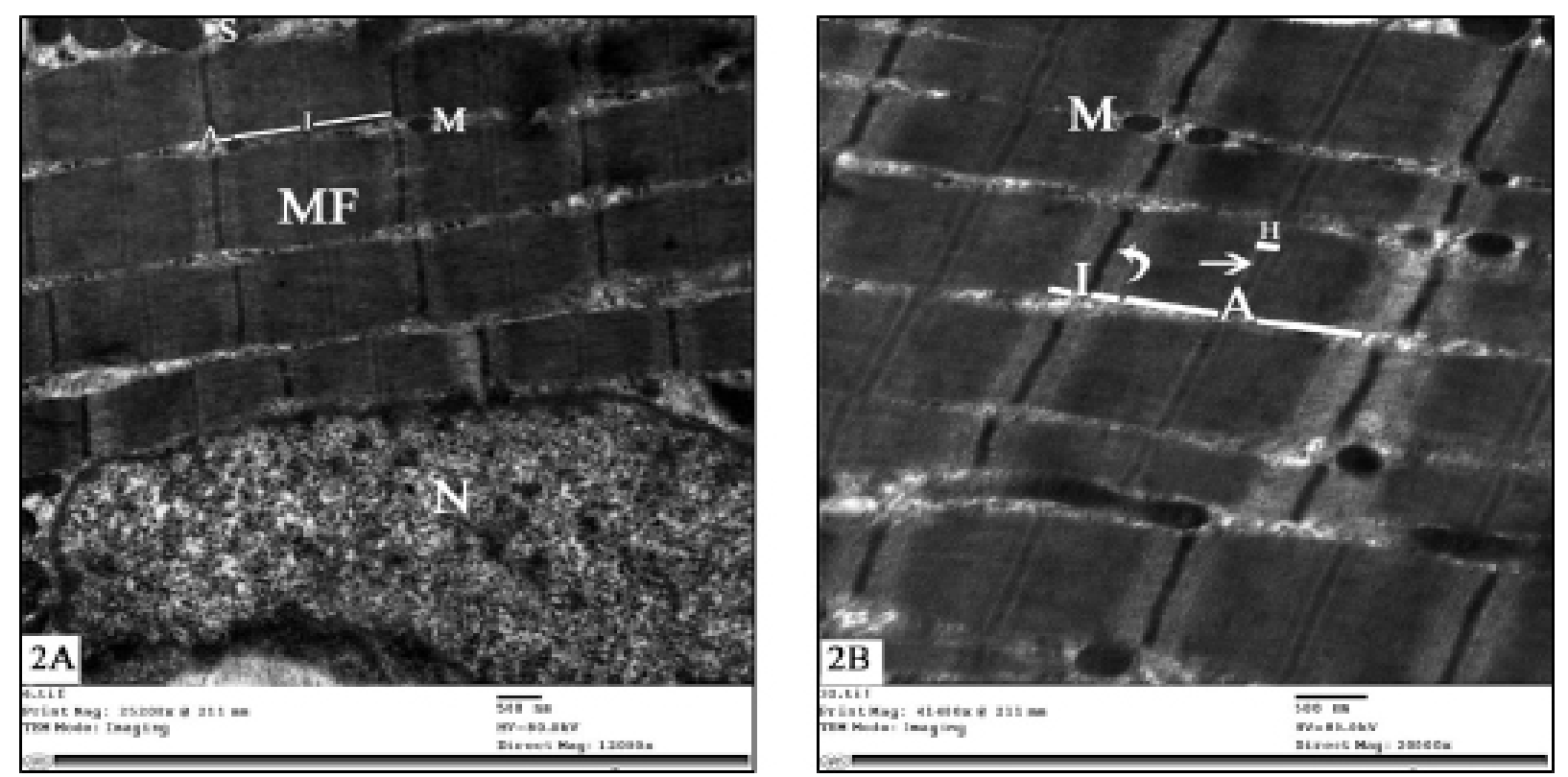

Fig. 2: Electron photomicrographs of the control group showing: A: Parallel regular arrangement skeletal muscle fibers with longitudinal parallel myofibrils (MF). Peripheral elongated euchromatic nucleus $(\mathrm{N})$, intermyofibrillar mitochondria $(\mathrm{M})$ as well as sarcoplasmic reticulum cisternae (S) at the junction of dark A band (A) and light I band (I) can be noted (x12000). B: Characteristic striations of alternating light and dark bands are observed. The more electron-dense $\mathrm{A}$ band (A) has a narrow, less electron-dense $\mathrm{H}$ zone $(\mathrm{H})$ bisected by $\mathrm{M}$ line (arrow), and the lucent I band (I) has a darker Z line (curved arrow). Note the presence of mitochondria (M) around the Z line (x20000). 

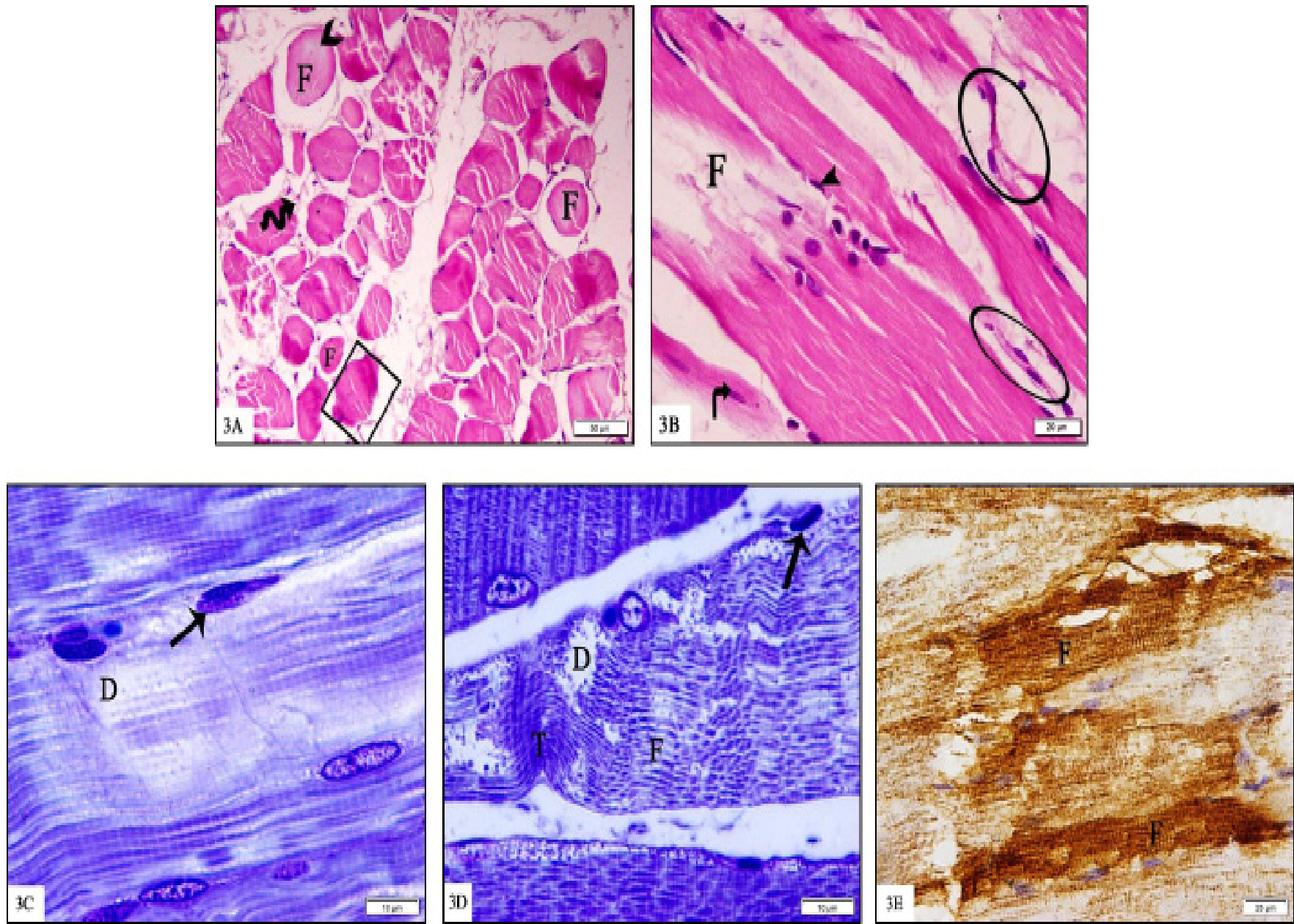

Fig. 3: Light photomicrographs of group II (Ator) demonstrating: A: T.S. of widely separated fibers, some of them are rounded and are surrounded by a halo of clear external rims (F). Many fibers start to acquire irregular outline (square) rather than polygonal with focal areas of deeply acidophilic sarcoplasm. Other fibers show focal areas of lightly stained sarcoplasm (bifid arrowhead). The C.T. endomysium (wavy arrow) appears widened (H\&E x200). B: L.S. showing disorganized fragmented and discontinued muscle fibers (F). Additionally, tapering of muscle fibers, which are about to separate (circles) and darkly stained nuclei (arrowhead) are noted. Some fibers exhibit pale nuclei that are centrally located (right-angled arrow) (H\&E x400). C: Semthin L.S. showing focal areas of sarcoplasmic dissolution (D) in a muscle fiber with lost transverse striations and peripheral dark nuclei (arrow) (Toluidine blue x1000). D: An attenuated muscle fiber (F) shows disorganized myofibrils with areas of sarcoplasmic dissolution (D) as well as intense sarcoplasmic staining (T) and dark nuclei (arrow) (Toluidine blue $\mathrm{x} 1000$ ). E: Widely extended positive sarcoplasmic immunoreaction of most muscle fibers (F) is observed (Immunohistochemical stain for cytochrome $\mathrm{C}$ x400). 

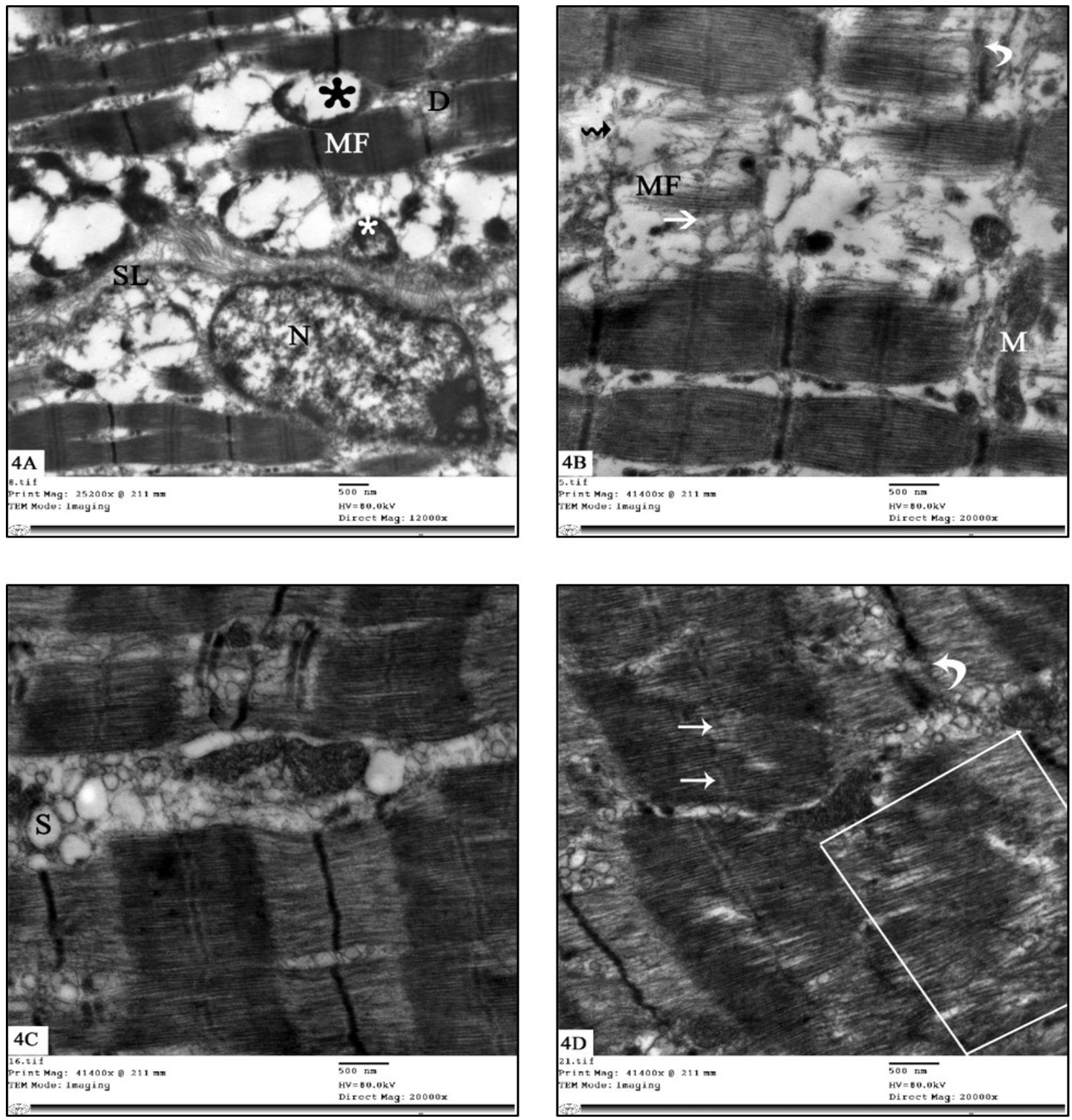

Fig. 4: Electron photomicrographs of Ator group showing: A: Myofibrils (MF) with areas of dissolution (D), subsarcolemal (SL) nucleus (N) with clumped chromatin and mitochondria (stars) with destructed cristae (x12000). B: Lysis and dissolution of many myofibrils (MF) with disrupted (curved arrow) or lost (wavy arrow) $\mathrm{Z}$ line, in addition to loss of parts of $\mathrm{M}$ line (arrow) are noted. A mitochondrion (M) appears disfigured and giant among the myofibrils (x20000). C: Other fields show dilated cisternae of sarcoplasmic reticulum (S) (x20000). D: Loss of the regular pattern of alternating dark A band and light I band (rectangle), disorganized interrupted $\mathrm{Z}$ line (curved arrow) and M line (arrows) are observed (x20000). 

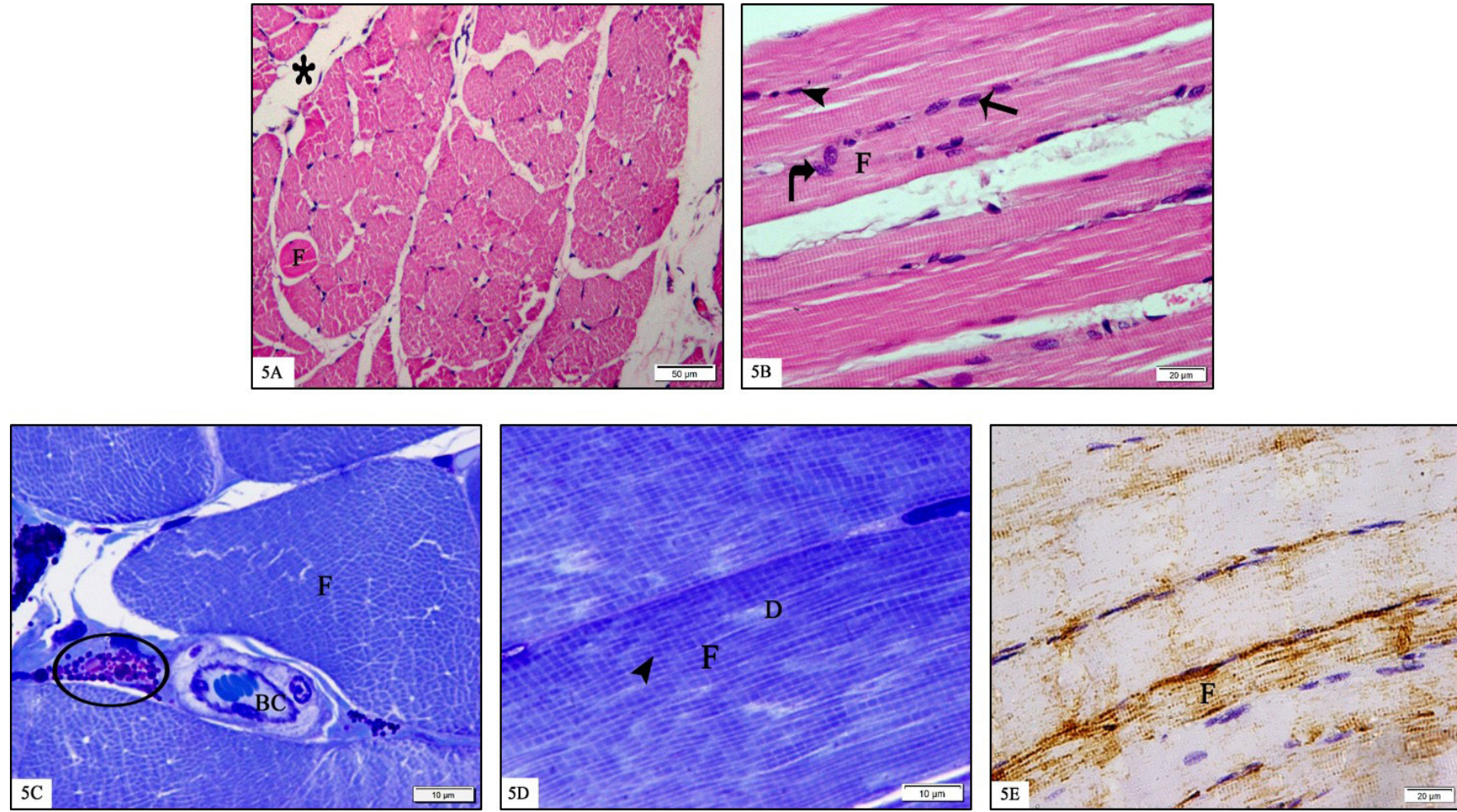

Fig. 5: Light photomicrographs of group III (Ator and ALF) illustrating: A: T.S. of bundles of apparently normal polygonal muscle fibers, which are separated by C.T. perimysium (star). A rounded muscle fiber with deeply eosinophilic sarcoplasm (F) is observed (H\&E x200). B: L.S. illustrating regularly arranged parallel muscle fibers (F) with pale oval nuclei either peripherally (arrow) or centrally (right-angled arrow) located. However, few dark nuclei (arrowhead) are observed (H\&E x400). C: Semthin T.S. showing polygonal muscle fibers (F) and a mast cell (circle) near blood capillary (BC) (Toluidine blue x1000). D: Semthin L.S. of muscle fibers (F) appears almost comparable to the control with clear transverse striations (arrowhead). However, few limited areas of sarcoplasmic dissolution (D) can be seen (Toluidine blue x1000). E: There are scattered areas of positive sarcoplasmic immunoreaction in some muscle fibers (F) (Immunohistochemical stain for cytochrome $\mathrm{C} \times 400)$.
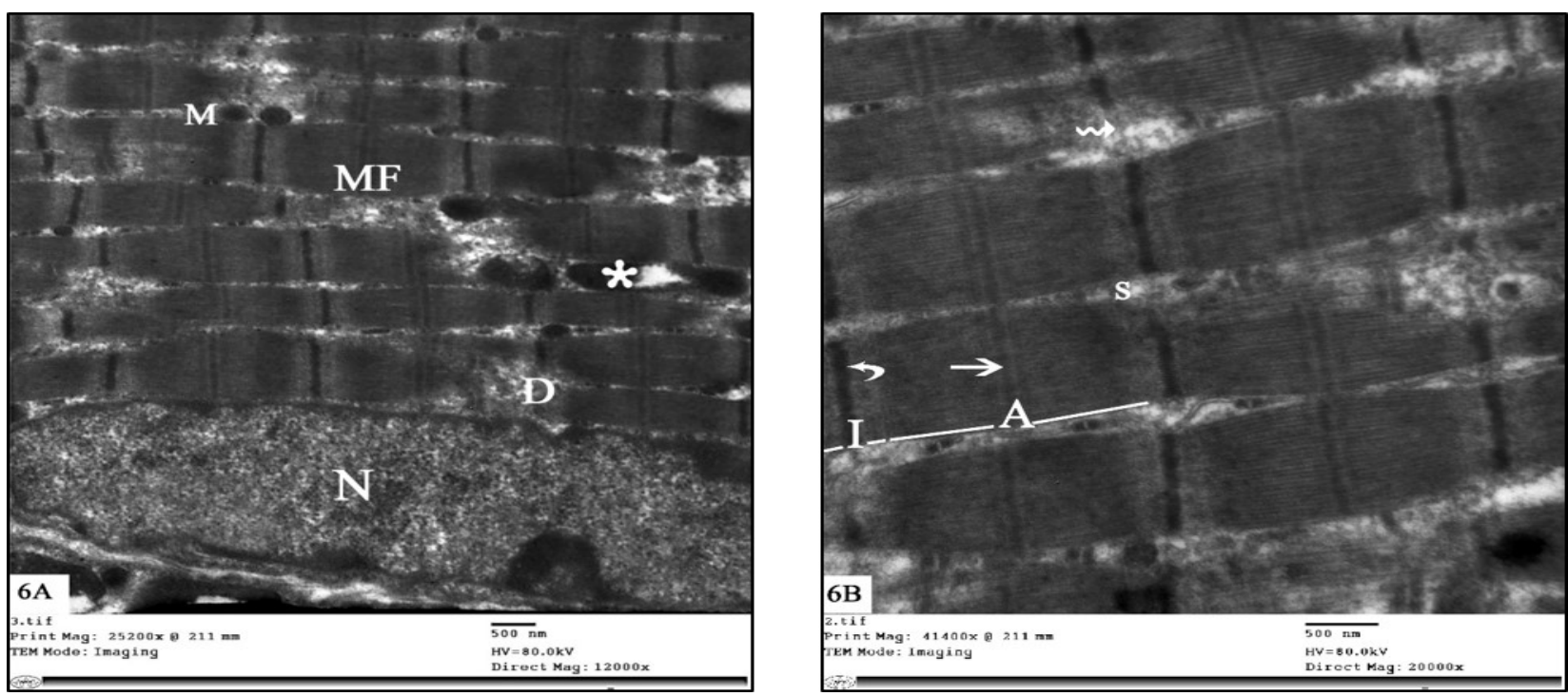

Fig. 6: Electron photomicrographs of Ator-ALF group showing: A: Parallel myofibrils (MF) that are arranged almost in register across the width of a muscle fiber. Note the appearance of few areas of myofibrillar dissolution (D). The mitochondria appear either normal (M) or with fragmented cristae (star). A peripheral nucleus $(\mathrm{N})$ with clumped chromatin is clearly seen (x12000). B: Clear regular striation nearly similar to that of the control group is formed of the dark A band (A) bisected by $\mathrm{M}$ line (arrow), and the light I band (I) with a darker Z line (curved arrow). Few areas of lost $Z$ line (wavy arrow) are observed. Additionally, apparently normal sarcoplasmic reticulum cisternae (S) are noticed (x20000). 


\section{DISCUSSION}

Statins have been efficiently used in the treatment of hypercholesterolemia. They are the most effective agents for reducing plasma cholesterol through inhibition of HMG-CoA reductase. Statins reduce the progression and may induce the regression of atherosclerosis resulting in significant reduction in cardiovascular morbidity and mortality ${ }^{[26]}$. The most adverse effects associated with Statins therapy are muscle-related ${ }^{[10]}$.

As myopathy is more likely to occur with lipophilic Statins ${ }^{[18]}$, Atorvastatin was chosen for this model because its elimination half-life is approximately 14 hours, a property that promotes drug's greater efficacy for lowering LDL-C compared with other Statins and may suggest drug accumulation. Furthermore, it is given in active form that extends its effect on HMG-CoA reductase. Therefore muscle damage was intensified by Ator; one of the commonly used Statins ${ }^{[27]}$.

In the current study, analysis of serum CPK revealed a significant increase in its mean values in Ator group versus control. This is consistent with the previously reported, where myopathy in rats is characterized by an elevation of CPK level along with muscle necrosis ${ }^{[28]}$. This CPK is a biochemical marker for muscle damage, its leak from the muscle cytosol following cell membrane damage can affect energy metabolism by lowering its ability to generate ATP (via adenosine diphosphate phosphorylation) ${ }^{[29]}$. Loss of this CPK can also weaken the structure of muscle (as it assists in formation of tight lattice in the M-region of sarcomeres), and deteriorates the stability of contracting filaments ${ }^{[30]}$.

Biochemically, increased-CPK could reflect the histological findings of myopathy that were shown in biceps femoris muscle. This muscle was chosen in particular as it is a large essential muscle in rat hind limb consisting of $77 \%$ of type IIB fibers and devoid from type I fibers ${ }^{[31]}$. Type II fibers are selectively subjected to Statins-induced myopathy. This observation reflects a clear relationship between the metabolic nature of individual muscle fibers and their sensitivity to Statin-induced necrosis. Fast-twitch muscles, containing predominantly glycolytic type IIB fibers, are considered more sensitive, compared to slowtwitch muscles that contain type I oxidative fibers ${ }^{[32]}$. Such selectivity is supported by the more evident biochemical alterations in fast twitch muscles upon Simvastatintreatment. This might be through reduction of the muscular content of proteins, glycogen, nucleic acids and lipids, with a concomitant rise in membrane fluidity ${ }^{[8]}$. Another explanation for the increased susceptibility of muscle damage in pale, glycolytic muscle fibers came from the lower peroxisome proliferator-activated receptor gamma coactivator-1 $\alpha$ (PGC-1 $\alpha)$ gene expression. This gene is overexpressed in type I fibers inducing mitochondrial biogenesis and protecting against the development of muscle atrophy, thus inhibited Statin-induced muscle damage in slow oxidative fibers ${ }^{[11]}$.

By LM examination, these myopathic findings were in the form of disorganization, discontinuation and fragmentation with loss of transverse striations of muscle fibers. Attenuated and tapered muscle fibers were separated by widened CT endomysium. Morphometrically, a significant reduction in the mean diameter of muscle fibers was recorded compared to the control group. This is in accordance with a former study that considered that findings as indicators for myofilament degeneration ${ }^{[33]}$. Additionally, some muscle fibers showed focal areas of deep sarcoplasmic staining indicating cytoplasmic protein denaturation ${ }^{[34]}$. As well, other fibers showed sarcoplasmic dissolution that might be related to myofilament-loss and destroyed mitochondria. Similar findings were reported by other researchers in a previous study ${ }^{[34]}$. Examination of different fields showed another sign of muscle fiber degeneration as some individual muscle fibers appeared rounded and were surrounded by a halo of clear external rim. This halo could be attributed to increased lipid deposition around the muscle fiber ${ }^{[18]}$.

A potential mechanism of such muscle damage features might be suggested based on these Statins treatment inhibits HMG-CoA reductase pathway and leads to impairment of protein synthesis with subsequent atrophy of muscle fibers ${ }^{[9]}$. This impairment probably results from the inhibition of farnesyl pyrophosphate and geranylgeranyl pyrophosphate production, which are end products of the mevalonate pathway. These compounds are essential for activation of regulatory proteins, which stimulate cell maintenance, growth and attenuating apoptosis process ${ }^{[1]}$. Furthermore, as HMG-CoA reductase inhibitors suppress the formation of mevalonate (precursor of cholesterol), the cholesterol conntent in sarcolemmal and mitochondrial membranes is reduced leading to instability of these membranes with impaired membrane function and abnormal calcium influx ${ }^{[35]}$. Moreover, the increased cytosolic calcium activates capsase- 3 resulting in cell death ${ }^{[36]}$. This might explain the presence of darkly stained nuclei within some muscle fibers in the present study.

The previous findings were confirmed immunohistochemically with a significant increase in the mean area percent of cytochrome $\mathrm{C}$ immunoreactivity versus control. These results are in agreement with what was reported formerly ${ }^{[18]}$. It was stated that cytochrome $\mathrm{C}$ is a protein complex that has a significant role in the process of oxidative phosphorylation and production of cellular adenosine triphosphate (ATP) ${ }^{[37]}$. Additionally the authors clarified that at times of cell stress, cytochrome $\mathrm{C}$ is released from the inter-membranous space of mitochondria into the cytoplasm and subsequently activates proteolytic enzymes called caspases causing protein degradation 
throughout the cell, resulting in the regulated process of apoptosis. In a prior study, Ator was reported to impair the function of skeletal muscle mitochondria leading to mitochondrial swelling and cytochrome $\mathrm{C}$ release into the sarcoplasm $^{[38]}$.

In Ator-treated group, other muscle fibers possessed pale central nuclei which may indicate start of regenerative process in focal areas. This finding was in agreement with $^{[33]}$. In response to a muscle injury, satellite cells are activated and start to proliferate; at this stage, they are referred as myoblasts which may form myotubules with central vesicular nuclei ${ }^{[39,40]}$.

The ultrastructural examination of biceps femoris muscle of Ator-treated group enforced the LM findings as most muscle fibers lost the alternating pattern of dark $\mathrm{A}$ band and light I band. Disrupted, disorganized Z-line and loss of parts of $\mathrm{M}$ line were noted. Besides, appearance of mitochondria with destructed cristae. Such findings coincide with those recorded in a previous study ${ }^{[34]}$. These were attributed to the changes that occurred to cell membranes structure modulating their fluidity. This in turn leads to disturbance of ion transporting system through altering $\mathrm{Na}+\mathrm{k}+$ pump function of the muscle fibers and consequently degeneration of muscle fibers and their membranous organelles ${ }^{[11]}$.

Moreover, the presence of disfigured giant mitochondria in Ator-treated group was suggested in a former study to sustain ATP production during apoptosis induced by reactive oxygen species. Whereas, oxidative stress may be a possible reason for the Simvastatin-induced histological and biophysiological changes ${ }^{[34]}$.

The possible mitochondrial dysfunction may explain the previously mentioned findings and subsequently influences the physical performance ${ }^{[5]}$. Hand in hand with the previous explanations, other researchers added that through inhibition of the HMG-CoA reductase, and supression of mevalonate (precursor of ubiqunione) formation, the ubiquinone production is inhibited. Ubiqunione is an essential coenzymes of the electron transport, as well as important antioxidant in mitochondria and lipid membranes. Therefore, Statins may change membrane properties and inhibit the production of mitochondrial ATP leading to impairment of energy metabolism of myocytes ${ }^{[18]}$. Furthermore, the deficiency of prenylated protein, another relevant compound to HMGCoA reductase pathway, leads to altered intracellular messaging, inducing vacuolation of the myofibers, swelling of organelles and finally results in apoptosis ${ }^{[41]}$. Such suggestion could explain the appearance of dilated cisternae of sarcoplasmic reticulum.

Calcitriol $\left[1,25(\mathrm{OH})_{2}\right.$ D3], an analog of vitamin $\mathrm{D}$, has beneficial effects on structural and functional abnormalities of skeletal muscle in uremic myopathy patients ${ }^{[42]}$.
However, we preferred to use ALF [1 $\alpha(\mathrm{OH})$ D3] for the following reasons. First, ALF-synthesis is simpler and less expensive as it is synthesized from cholesterol. Second, ALF exhibits lower risk of developing hypercalcemia and hypercalciuria as it requires 25 -hydroxylation in the liver for activation after oral administration and intestinal absorption. Therefore, it displays a retarded plasma curve in comparison to Calcitriol ${ }^{[43]}$. This activation step of ALF is not affected in liver disease except in very advanced stages of primary biliary cirrhosis ${ }^{[13]}$.

In a prior study, comparing the efficacy of ALF versus plain vitamin D on muscle function, bone metabolism, joint pain, and cytokine levels, ALF recorded significant improvement in strength of muscle compared to plain vitamin $\mathrm{D}^{[44]}$. Other researchers clarified that nutritional supplementation with plain vitamin D (cholecalciferol which needs an activation step in the liver and then in the kidney) is effective only in vitamin D deficient patients with normal kidney function. On the other hand, ALF is efficient in both vitamin D deplete and sufficient patients resulting into a dose dependent elevation of D-hormone action at different target tissues ${ }^{[13]}$. Along with that, ALF does not require the activation step in the kidneys ${ }^{[45]}$, therefore, the use of ALF may overcome age- or disease-related decline in renal function that could affect the 1-hydroxylating capacity ${ }^{[46]}$. Consequently, ALF is considered more superior prodrug of the D-hormone than plain vitamin $\mathrm{D}$.

In the current study, Ator-ALF treated group recorded a significant decrease in the level of serum CPK versus group II and non significant difference versus control. This might explain the histological improvement of LM findings that appeared in the form of well-organized muscle fibers nearly similar to the control with clear regular striations This was confirmed morphometrically by a non significant difference in mean diameter of muscle fibers versus group I. Moreover, transverse sections of biceps femoris muscle showed bundles of almost normally appearing polygonal muscle fibers. While, few rounded muscle fibers with deeply eosinophilic sarcoplasm and longitudinal muscle fibers with few dark nuclei were still noted.

The existence of pale centrally located nuclei in some muscle fibers of this group could be promoted by the development of regenerated fibers that show a large proportion of nuclei remain in central position $^{[39]}$. Also, Haschek et al. attributed such finding to the fact that following muscle fibers destruction, the sarcoplasmic debris is removed by invading macrophages. Then the persisting sarcolemmal tubes become populated by myoblasts, which join to form myotubes that bridge the gap of disrupted sarcoplasm in damaged myofibers. Subsequently, the regenerated muscle fibers cannot be identified from adjacent unaffected fibers ${ }^{[4]]}$.

In some fields of group III, mast cells were noted near blood capillaries that could be explained by the occurrence 
of microenvironment changes as a result of plasma membrane disruption. These changes were chemotactic for the mast cells that play a great role in muscle regeneration and repair $^{[48]}$. After their activation, mast cells can synthesize variable mediators, through which host defense, leukocyte recruitment, and tissue repair can be achieved ${ }^{[49]}$. Furthermore, the previous authors added that mast cells can affect myoblast proliferation in vivo, but this effect predominantly related to their modulation of macrophage recruitment. These macrophages also participate in tissue repair by their ability to phagocytose necrotic fibers and stimulate fiber regeneration via growth factors release ${ }^{[50]}$.

All the previous LM findings were also supported immunohistochemically by the significant decrease in the mean area percent of cytochrome $\mathrm{C}$ immunoreaction versus group II and non significant difference versus control. Another proof for this histopathological improvement of group III was clarified at the ultrastructure level. Parallel myofibrils were arranged almost in register across the width of a muscle fiber with clear regular striation nearly similar to that of the control group. However, few areas of myofibrillar dissolution and mitochondria with fragmented cristae were observed.

These biochemical and histological improvements achieved by ALF in Ator- ALF treated group could be explained by the hypothesis, which illustrated that vitamin D receptors in skeletal muscle modulate various transcription factors in muscle cells, promoting muscle cell proliferation and differentiation into mature type II muscle fibers ${ }^{[51]}$. Additionally, vitamin D is responsible for the regulation of calcium metabolism in muscles and the control of muscle contraction and relaxation ${ }^{[46]}$. Furthermore, vitamin $\mathrm{D}$ was proved to have anabolic effect on muscular tissue, as it promotes synthesis of muscle cytoskeletal protein $^{[19]}$. Additional enforcement was attained from the reported positive effects of ALF administration on skeletal muscle in glucocorticoids -treated rats, where it inhibited muscle atrophy, muscle fatigue and preserved muscle strength ${ }^{[52]}$.

Another explanation for such improvements in group III was based on the possible relationship between vitamin D and Atorvastatin. Vitamin D being an inducer of Cytochrome P (CYP3A4) enzyme that stimulates the metabolism of some Statins (like Atorvastatin), can result in less toxic metabolites ${ }^{[53,54]}$. Therefore, it was suggested that the concurrent administration of vitamin $\mathrm{D}$ with Atorvastatin might reduce the risk of its adverse effects on muscle $^{[53]}$

\section{CONCLUSION}

Atorvastatin induced obvious muscle degeneration mainly through sarcolemmal and mitochondrial membranes instability and mitochondrial dysfunction. The concomitant administration of Alfacalcidol ameliorated Ator-induced myopathy and kept muscle fibers structure, based on lower CPK level, decreased cytochrome $\mathrm{C}$ immunoexpression and nearly normal muscle fibers appearance upon light and electron microscopic examination.

Alfacalcidol may be recommended for hypercholesteremic patients using Statins especially who are at risk of vitamin D insufficiency.

\section{CONFLICT OF INTEREST}

There are no conflicts of interest.

\section{REFERENCES}

1. Sadeeqa S, Maqsood M, Ahmad M. Prevalence of statin induced myopathy in Lahore, Pakistan. Pak J Pharm Sci. 2018 31:617-622.

2. Stroes ER, Thompson PD, Corsini A, Vladutiu GD, Raal FJ, Ray KK, Roden M, Stein E, Tokgözoğlu L, Nordestgaard BG, Bruckert E, Backer GD, Krauss RM, Laufs U, Santos RD, Hegele RA, Hovingh GK, Leiter LA, Mach F, März W, Newman CB, Wiklund $O$, Jacobson TA, Catapano AL, Chapman MJ, Ginsberg HN. Statin-associated muscle symptoms: impact on statin therapy-European Atherosclerosis Society Consensus Panel Statement on Assessment, Aetiology and Management. European Heart Journal. 2015; 36: 1012-1022.

3. Hobbs FR, Banach M, Mikhailidis DP, Malhotra A, Capewell S. Is statin-modified reduction in lipids the most important preventive therapy for cardiovascular disease? A pro/con debate. BMC Medicine. 2016; 14:4-12.

4. Goldstein JL, Brown MS. A Century of Cholesterol and Coronaries: From Plaques to Genes to Statins. Cell. 2015; 161:161-172.

5. Muraki A, Miyashita K, Mitsuishi M, Tamaki M, Tanaka K, Itoh H. Coenzyme Q10 reverses mitochondrial dysfunction in atorvastatin-treated mice and increases exercise endurance. J Appl Physiol. 2012; 113: 479-486.

6. Ramkumar S, Raghunath A, Raghunath S. Statin Therapy: Review of Safety and Potential Side Effects. Acta Cardiol Sin. 2016; 32: 631-639.

7. Sadowitz B, Maier KG, Gahtan V. Statin Therapy_Part I: The Pleiotropic Effects of Statins in Cardiovascular Disease. Vascular and 
Endovascular Surgery. 2010; 44: 241-251.

8. Norata GD, Tibolla G, Catapano AL. Statins and skeletal muscles toxicity: from clinical trials to everyday practice. Pharmacol Res. 2014; 88:107-13.

9. Hassan NF, El- Bakry NA, Shalaby NM, Ghobara MM, Bayomi NA. Histological Study of the Effect of Simvastatin on the Skeletal Muscle Fibers in Albino Rat and the Possible Protective Effect of Coenzyme Q 10. Egypt. J. Histol. 2009; 31: $216-226$.

10. Banach M, Rizzo M, Toth PP, Farnier M, Davidson $\mathrm{MH}$, Al-Rasadi $\mathrm{K}$, Aronow WS, Athyros V, Dragan M, Djuric DM, Ezhov MV, Greenfield RS, Hovingh GK, Kostner K, Serban C, Lighezan D, Fras Z, Moriarty PM, Muntner P, Goudev A, Ceska R, Nicholls SJ, Broncel M, Nikolic D, Pella D, Puri R, Rysz J, Wong ND, Bajnok L, Jones SR, Ray KK, Mikhailidis DP. Statin intolerance an attempt at a unified definition. Expert Opinion on Drug Safety. 2015; 14: 935-955.

11. Ahmed S, Saber EA, Hamouda AH, Rifaai RA. Structural Changes in the Skeletal Muscle Fiber of Adult Male Albino Rat Following Atorvastatin Treatment; the Possible Mechanisms of Atorvastatin Induced Myotoxicity. J Cytol Histol. 2017; 8: 442.

12. Khajuriaa DK, Dishaa C, Razdana R, Mahapatrab D. Additive effect of zoledronic acid and alfacalcidol in the treatment of disuse osteoporosis in rats. Rev Bras Reumatol. 2015; 55:240-250.

13. Ringe JD, Schacht E. Improving the outcome of established therapies for osteoporosis by adding the active D-hormone analog alfacalcidol Rheumatol Int. 2007; 28:103-111.

14. Pašalić KS, Gošić K, Gavrilović A, Vojinović J. Additional impact on muscle function when treating active rheumatoid arthritis patients with high alfacalcidol doses. Vojnosanit Pregl. 2017; 74: 1036-1042.

15. Glueck CJ, Abuchaibe C, Wang P. Symptomatic myositis-myalgia in hypercholesterolemic statin-treated patients with concurrent vitamin $\mathrm{D}$ deficiency leading to statin intolerance may reflect a reversible interaction between vitamin $\mathrm{D}$ deficiency and statins on skeletal muscle. Med Hypotheses. 2011; 77:658-61.

16. Schmechel A, Grimm M, El Armouche
A $\mathrm{H}$, Eschenhagen $\mathrm{T}$. Treatment with atorvastatin partially protects the rat heart from harmful catecholamine effects. Cardiovasc. Res. 2009; 82: 100-106.

17. Fahmi HM, Kamel ES, Ouies SM, Abd El-Naeem AF. Role of Alendronate and Alfacalcidol in Protection Against Steroid Induced Osteoporosis in Adult Male Albino Rats. Med. J. Cairo Univ. 2017; 85: 161-171.

18. Khalil MS, Khamis N, Al-drees A, Abdulghani HM. Does coenzyme-Q have a protective effect against atorvastatin induced myopathy? A histopathological and immunohistochemical study in albino rat. Histol Histopathol. 2015; 30: 383-390.

19. Kasukawa Y, Miyakoshi N, Maekawa S, Nozaka K, Noguchi H, Shimada Y. Effects of alfacalcidol on muscle strength, muscle fatigue, and bone mineral density in normal and ovariectomized rats. Biomed Res. 2010; 31: 273-9.

20. Pourghasem M, Nasiri E, Shafi H. Early renal histological changes in Alloxan-induced diabetic rats. Int J Mol Cell Med. 2014; 3: 11-15.

21. Kiernan JA. Histological and histochemical methods: Theory and practice. 5th ed, Scion Publishing, Banbury, UK 2015; pp. 111-162.

22. Javid J, Mir R, Julka PK, Ray PC, Saxena A. Extracellular Cytochrome $\mathrm{C}$ as a biomarker for monitoring therapeutic efficacy and prognosis of non-small cell lung cancer patients. Tumor Biol. 2015; 36:4253-4260.

23. Suvarna K, Layton C, Bancroft J. Immunohistochemical techniques and Transmission electron microscopy In: Bancroft's Theory and practice of Histological Techniques, 7th ed, Churchill Livingstone Elsevier, Oxford. 2013. pp. 381426- and 492-538.

24. Dykstra MJ, Reuss LE. Staining methods for semithins and ultra thins. In: Biological electron microscopy, theory, techniques and troubleshooting. 2nd ed, Kluwer Academic Publishers/Plenum Publishers. 2003. pp.175- 196.

25. Emsley R, Dunn G, White IR. Mediation and moderation of treatment effects in randomised controlled trials of complex interventions. Stat Methods Med Res. 2010; 19: 237-270.

26. Rozman D, Monostory K. Perspectives of the 
non-statin hypolipidemic agents. Pharmacology \& Therapeutics. 2010; 127: 19-40.

27. Abd Elhaleem ZA, Elsayed A. Coenzyme Q10 ameliorates Statin-induced myotoxicity: A Biochemical and Histological Study. Journal of Pharmacology and Toxicology. 2011; 6:258-271

28. El-Ganainy SO, El-Mallah A, Abdallah D, Khattab MM, Mohy El-Din MM, El-Khatib AS. Elucidation of the Mechanism of AtorvastatinInduced Myopathy in a Rat Model Toxicology. 2016; 359-360: 29-38.

29. Elshama SS, El-Kenawy AE, Osman HH.Curcumin improves atorvastatin-induced myotoxicity in rats: Histopathological and biochemical evidence International Journal of Immunopathology and Pharmacology. 2016; 29: 1-11

30. Moustafa AM. Boshra V. The possible role of L-carnitine on the skeletal muscle of ovariectomized rats $\mathrm{J}$ Mol Hist. 2011; 42: 217-225.

31. Eng CM, Smallwood LH, Rainiero MP, Lahey M, Ward SR, Lieber RL. Scaling of muscle architecture and fiber types in the rat hindlimb. J. Exp. Biol. 2008; 211: 2336-2345.

32. Westwood FR, Bigley A, Randall K, Marsden AM, Scott RC. Statin-Induced Muscle Necrosis in the Rat: Distribution, Development, and Fibre Selectivity Toxicologic Pathology. 2005; 33 2005: 246-257.

33. El Dawi, Hassan SA; Elgharabawy, Gamal S; El Sharkawy, Ezz El-Dein; Moustafa, Abd El Ghany A; Amr, Ibraheim M; Bayomy, Osama IR. Histological Studies on Skeletal Muscles of Albino Rats under the Effect of Atorvastatin. The Egyptian Journal of Hospital Medicine. 2013; 53:883-903.

34. Abdel Hamid KM, Abdel Mola AF, Meligy FY, Abd Allah ESH. The Possible Protective Role of Ginger Extract Versus Vitamin E Against Simvastatin-Induced Skeletal Myotoxicity in Adult Male Albino Rats: Histological, Physiological and Biochemical Study. The Egyptian Journal of Histology. 2017; 40: 156-168.

35. Harris BT, Mohila CA. Essential Muscle Pathology for the Rheumatologist. Rheum Dis Clin N Am. 2011; 37: 289-308.

36. Abd TT, Jacobson TA. Statin-induced myopathy: a review and update. Expert opinion on drug safety.
2011; 10: 373-387.

37. Mescher AL. The cytoplasm. In: Junqueira's Basic Histology: Text and Atlas, 14th ed, Mc Graw Hill, New York, Chicago, San Francisco. 2016. pp. 17-52.

38. Kaufmann P, Török M, Zahno A, Waldhauser KM, Brecht K, Krähenbühl S. Toxicity of statin on rat skeletal muscle mitochondria. Cell Mol. Life Sci. 2006; 63: 2415-2425.

39. Turk R, Sterrenburg E, de Meijer E, van Ommen G, den Dunnen J, Hoen P. Muscle regeneration in dystrophin-deficient $\mathrm{mdx}$ mice studied by gene expression profiling. BMC Genomics. 2005; 6: 98-113.

40. Tedesco FS, Dellavalle A, Diaz-Manera J, Messina G, Cossu G. Repairing skeletal muscle: regenerative potential of skeletal muscle stem cells. Journal of clinical investigation. 2010; 120: 11-19.

41. Abdulrazaq M, Hamdan F, Al-Tameemi W. Electrophysiologic and clinico-pathologic characteristics of statin-induced muscle injury. Iran J Basic Med Sci. 2015; 18: 737-744.

42. Acevedo LM, López I, Peralta-Ramírez A, Pineda C, Chamizo VE, Rodríguez M, Aguilera Tejero E, Rivero JL. High-phosphorus diet maximizes and low dose calcitriol attenuates skeletal muscle changes in long-term uremic rats. J Appl Physiol. 2016; 120: 1059-1069.

43. Cianferotti L, Cricelli C, John A, Kanis JA, Nuti R, Reginster J, Ringe JD, Rizzoli R, Brandi ML. The clinical use of vitamin D metabolites and their potential developments: a position statement from the European Society for Clinical and Economic Aspects of Osteoporosis and Osteoarthritis (ESCEO) and the International Osteoporosis Foundation (IOF). Endocrine. 2015; 50: 12-26.

44. Ringe JD, Dorst A, Faber H, Schacht E, Rahlfs VW. Superiority of alfacalcidol over plain vitamin $\mathrm{D}$ in the treatment of glucocorticoid-induced osteoporosis Rheumatol Int. 2004; 24: 63-70.

45. Nagaoka H, Terajima M, Yamada S, Azuma $Y$, Chida T, Yamauchi M. Alfacalcidol Enhances Collagen Quality in Ovariectomized Rat Bones. Journal of Orthopaedic Research. 2014; 32: 1030-1036.

46. Schacht E, Richy F, Reginster JY. The therapeutic effects of alfacalcidol on bone strength, 
muscle metabolism and prevention of falls and fractures. J Musculoskelet Neuronal Interact. 2005; 5: 273-284.

47. Haschek WM, Rousseaux CG, Wallig MA. Cardiovascular and skeletal muscle system. In: Fundamentals of toxicologic pathology, 2nd ed, San Diego, CA: Academic Press; 2010. pp. 371.

48. Kharraz Y, Guerra J, Mann CJ, Serrano AL, Muñoz-Cánoves P. Macrophage plasticity and the role of inflammation in skeletal muscle repair. Mediators of Inflammation. 2013; 2013: 9 pages.

49. Galli SJ, Tsai M. Mast cells: versatile regulators of inflammation, tissue remodeling, host defense and homeostasis. J Dermatol Sci. 2008; 49: 7-19.

50. Brunelli S, Rovere-Querini P. The immune system and the repair of skeletal muscle. Pharmacol Res. 2008; 58: 117-121.
51. Rasheed K, Sethi P, Bixby E. Severe Vitamin D Deficiency Induced Myopathy Associated with Rhabydomyolysis. North American Journal of Medical Sciences. 2013; 5: 334-336.

52. Miyakoshi N, Sasaki H, Kasukawa Y, Kamo K, Shimada Y. Effects of a vitamin D analog, alfacalcidol, on bone and skeletal muscle in glucocorticoid-treated rats. Biomed Res. 2010; 31: 329-336.

53. Bhattacharyya S, Bhattacharyya K, Maitra A. Possible mechanisms of interaction between statins and vitamin D. Q J Med 2012; 105: 487-491.

54. Riche K D, Arnall J, Rieser K, East HE, Riche DM. Impact of vitamin D status on statin-induced myopathy. Journal of Clinical and Translational Endocrinology. 2016; 6: 56-59. 
الملغص العربى

\title{
هل يمكن لألفاكالسيدول تحسين الاعتلال العضلي المُستحث من أتورفاستاتين في ذكور الجرذان

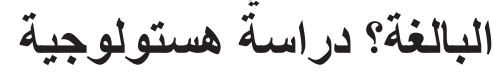

\author{
داليا فتحي الايب ، ميرا فاروق يوسف،مروة محمد يسرى، إيمي محمد احمد
}

\section{قسم علم الأنسجة_ كلية الطب - جامعة القاهرة}

المقدمة: يعد اتورفاستاتين (أتور)، نوع من ستاتين،العلاج الامثل لخفض كوليسترول الدام. معظم الآثار السلبية المرتبطة بعلاج

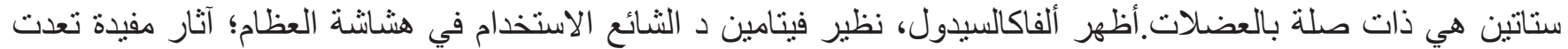
الهيكل العظمي لتشمل العضلات. الهدف من البحث: اكتثاف التأثثر الوقائي المحتمل لألفاكالسيدول في الجرذان المصابة بالاعتلال العضلي المُستحث من تعاطي أتور.

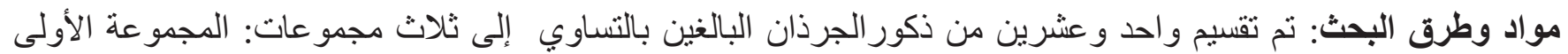

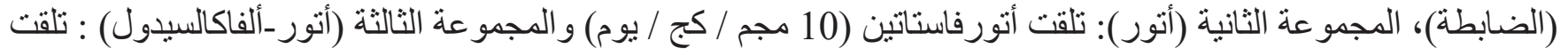

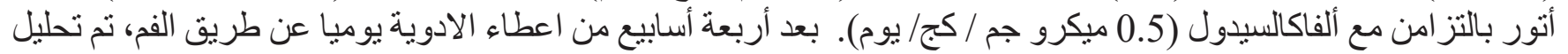

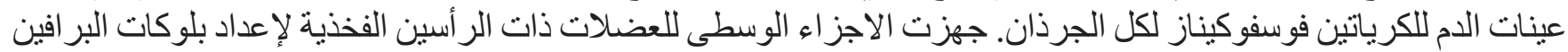

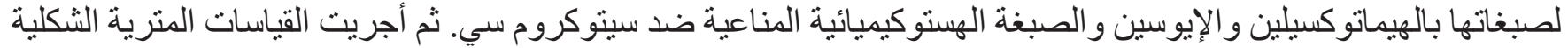

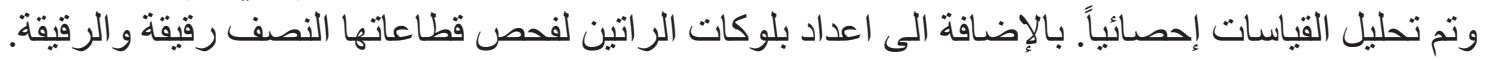

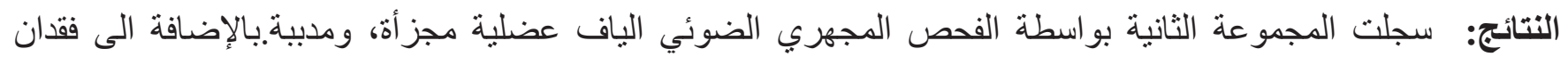

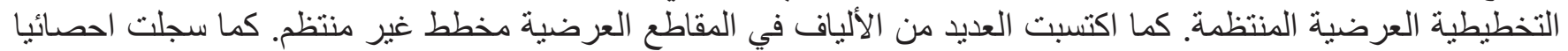

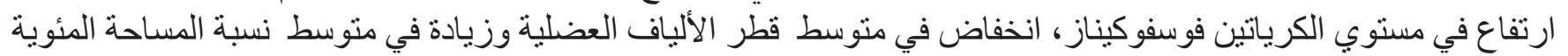

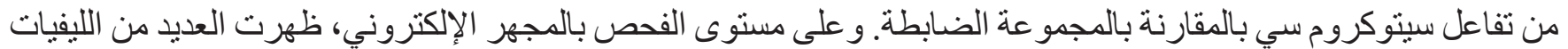

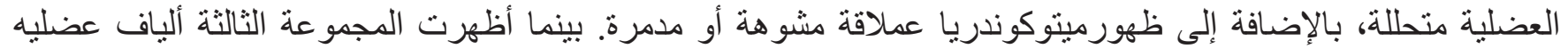

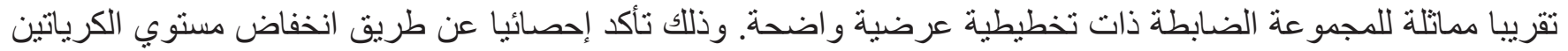

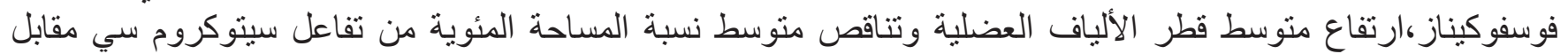
المجمو عة الثانية.في حين لوحظ بو اسطة الفحص الدقيق مساحات قليلة من الليفيات العضلية المتحللة.

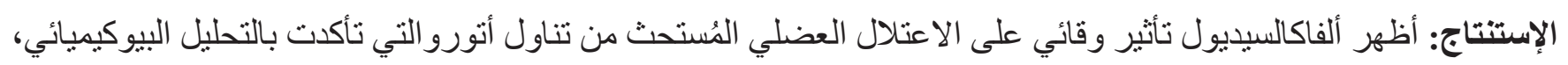

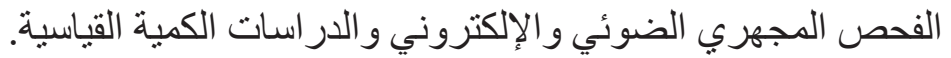

